\title{
ON VARIATIONS IN THE CURRENT AT THE SEVEN STONES LIGHT VESSEL
}

\author{
By L. H. N. Cooper, D.Sc., \\ The Plymouth Laboratory \\ Commander A. L. LAWFORD, R.N. (Rtd.) \\ National Institute of Oceanography, Wormley \\ and Instructor Commander V. F. C. VELEY, R.N.* \\ (Text-figs. I-4)
}

Measurements of current at the Seven Stones Light Vessel, $50^{\circ} 03.5^{\prime} \mathrm{N}$. lat., $6^{\circ} 05 \cdot \mathrm{I}^{\prime} \mathrm{W}$. long. (for position, see Cooper, $1960 \mathrm{~b}$, fig. I) were first made with the Carruthers Drift Indicator between 17 August and 15 September I933 (Carruthers, 1934). The much longer series with the Vertical Log between July 1939 and April I94I showed average travel of the residual current at a rate of 2.5 miles per day towards east-south-east ( $110^{\circ}$ true) (Carruthers, Lawford \& Veley, I95I). It was shown clearly that there was a strong causal connexion between the direction and strength of the wind and direction and strength of current, but that there were evidently other factors concerned as well. These current measurements were not easy to reconcile with deductions from the observed distributions of temperature and salinity in the area (Matthews, I914; Harvey, 1925, 1929; Cooper, 1960b). A rational explanation could be achieved if it is assumed that the passage of water from the English Channel to the Bristol Channel occurs intermittently and is confined to a narrow current close into Lands End. This 'corner current' rarely extends as far west as the Seven Stones Light Vessel.

During 1950 as a result of R.V. 'Sabella's' work on 20-24 April 1950 we deduced from a study of the observed winds the probable current at the Seven Stones for the 3 days when R.V. 'Sabella' was in the vicinity (Table I). Around $2 \mathrm{I}-23$ April the predicted residual current was, no doubt, setting towards $120^{\circ}$. This is close to the direction $110^{\circ}$ (true) computed for the average water movement over the whole period of 600 days in 1939-4I. On 2I April 'Sabella' Stations 30 and 29 bracketed the position of the light vessel and Stations 27 and 28 were 8 and I2 miles to the westward and immediately north of the Scilly Islands; they were occupied by water of relatively low temperature and salinity. This is a consistent picture of a movement of water

\footnotetext{
* In 1950 at the Hydrographic Department, Admiralty; present address: H.M.S. Ariel, Lee-on-Solent, Hants.
} 
TABLE 1. PREDICTED RESIDUAL WATER MOVEMENTS AT SEVEN STONES LIGHT VESSEL

Date, April 1950

Intrinsic water movement irrespective of tides

Water movement produced

by winds

Residual water movement

\begin{tabular}{|c|c|}
\hline $\begin{array}{l}\text { Speed } \\
\text { m.p.d. } \\
2\end{array}$ & $\begin{array}{r}\text { Dir. } \\
50^{\circ}\end{array}$ \\
\hline $4{ }_{1}$ & $155^{\circ}$ \\
\hline 4 & $125^{\circ}$ \\
\hline
\end{tabular}

\begin{tabular}{|c|c|}
\hline $\begin{array}{l}\text { Speed } \\
\text { m.p.d. } \\
3\end{array}$ & $\begin{array}{l}\text { Dir. } \\
100^{\circ}\end{array}$ \\
\hline $6 \cdot{ }_{4}$ & $15^{\circ}$ \\
\hline $7{ }_{5}$ & $40^{\circ}$ \\
\hline
\end{tabular}

from the north-west. The water at Stations 27 and 28 had much in common with that at Station 89, I4 miles to the north on 30 April. This distribution is also consistent with the eastern sector of an eddy or rising centre conditioned by the distribution of density during a period of warming up within and around Scilly (Cooper, I960a).

Again (Cooper, $1960 b$ ) the distribution of temperature and salinity west and north of Cornwall in April 1950 (Cooper, I960 a, fig. 4) could be understood only if a very considerable transport of water had occurred during the preceding neap tides but had been suppressed by the spring tides occurring when the observations were made. Also in the observations of temperature and salinity at the Seven Stones in 1950 (Cooper, 1960 b, fig. 2) there is a suggestion of lunar periodicity in summer.

We therefore further analysed the I939-4I current observations for the effect of tide and season. There are three restrictions inherent in the analysis. (i) The current is much influenced by wind and by factors at a distance from the Seven Stones. Over the whole period, the strength of the mean residual local wind was only $3 \%$ of the maximum strength recorded. But when individual lunar months are considered, the strength of the mean residual local wind may be as much as $30 \%$ of the maximum and cannot then be neglected. (ii) The vertical log current meter used reads the direction of water movement only to within $\pm 22 \frac{1}{2}^{\circ}$. Summing and averaging may considerably reduce the error of the mean measurements. (iii) In these computations, the magnitude and direction of the residual water movement were treated independently, i.e. the directions (or magnitudes) were 'summed' algebraically and divided by the number of days involved.

The first step in the analysis was to determine the mean direction of the residual water movement during each of 22 consecutive lunar months (Fig. I, lower). The direction varied between $90^{\circ}$ and $150^{\circ}$, the mean for the whole period being $\mathrm{I} \mathrm{I}_{4}^{\circ}$.

The variation in direction of the residual water movement about its over-all mean seems to be periodic, being to the north of the mean in winter and spring and to the south during summer and early autumn. Most of the 'peaks' on the plot coincide with periods when the residual wind was either very 
strong or blew from directions at right angles to the mean direction of the residual water movement. Taking this into account, it is suggested that the intrinsic residual water movement is most northerly in December and most southerly in July.

The variation in flow (magnitude) of the residual water movement per lunar month (Fig. I, upper) is not as clear as the variation in direction. However we suspect that at the time a long-term periodic factor was decaying,

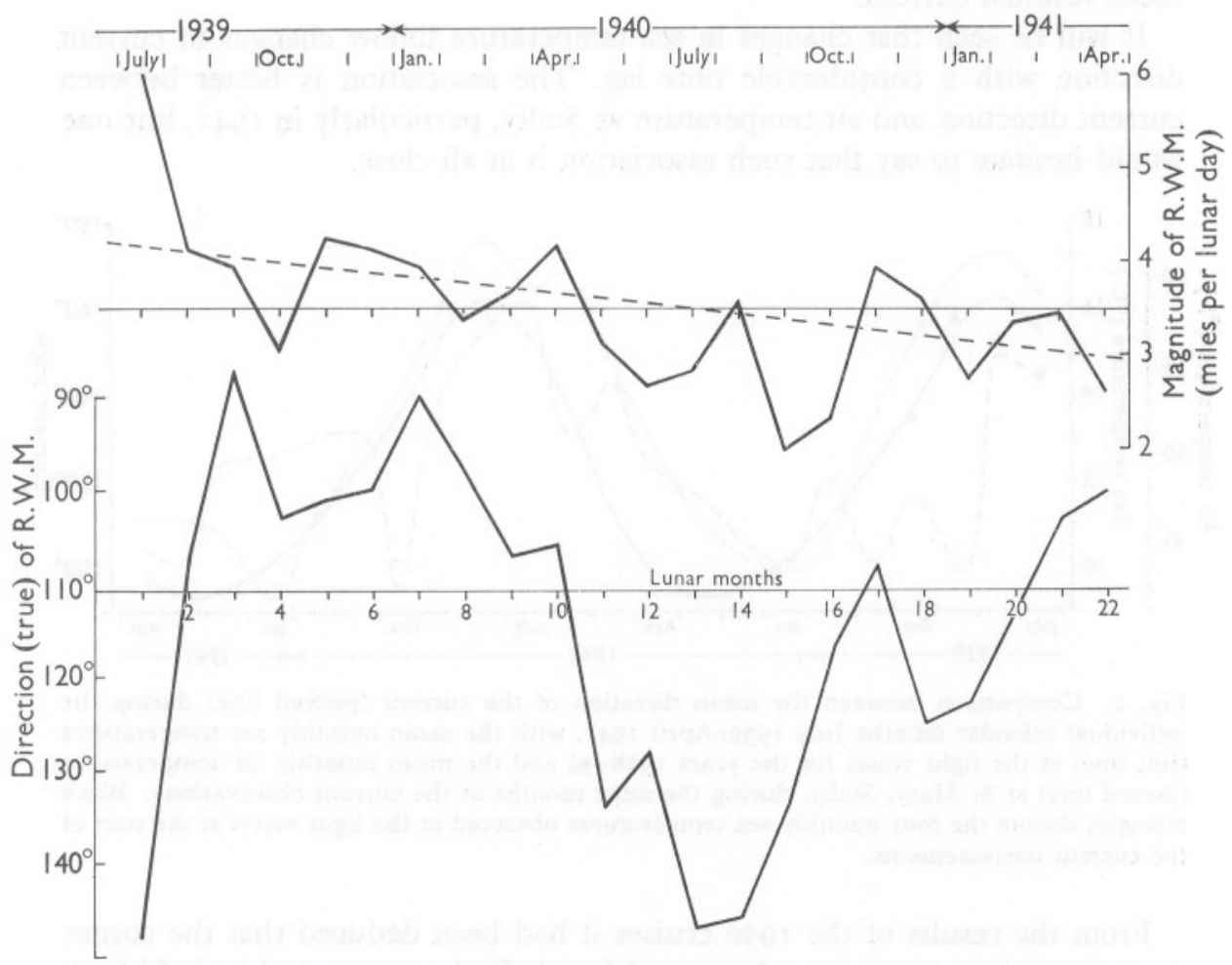

Fig. I. Residual water movements at the Seven Stones Light Vessel during individual lunar months between July I939 and April I94I. Upper panel, magnitude in miles per lunar day; lower panel, true direction.

so that the plot of mean values should be read about the pecked line tentatively drawn in. It would seem that the mean magnitude of the residual water movement may be higher in winter and spring and lower in summer and autumn.

The high magnitude for the residual water movement in July 1939 provides a problem; however, the mean wind during the lunar month favoured this residual water movement and may have accounted for about 2 miles per day of the 6 miles per day found. 
The direction of the current is not closely tied to either sea or air temperatures. For this comparison calendar months are more convenient (Fig. 2).

It is most unfortunate that due to war conditions the temperature records were maintained only for the first 4 months of the Vertical Log measurements so that a direct comparison between sea temperature and current direction cannot be made. A comparison is here made between the monthly mean temperature over the years $1928-39$ (Cooper, $1960 b$, table I) and the monthly mean residual current.

It will be seen that changes in sea temperature follow changes in current direction with a considerable time lag. The association is better between current direction and air temperature at Scilly, particularly in I94I, but one would hesitate to say that such association is at all close.

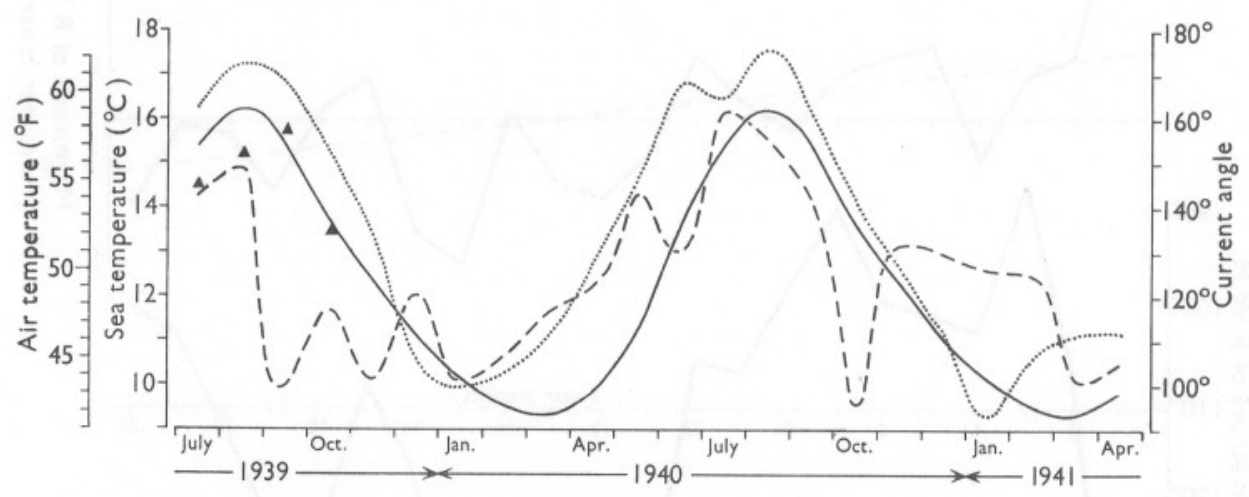

Fig. 2. Comparison between the mean direction of the current (pecked line) during the individual calendar months July I939-April I94I, with the mean monthly sea temperatures (full line) at the light vessel for the years 1928-39 and the mean monthly air temperatures (dotted line) at St Mary, Scilly, during the same months as the current observations. Black triangles denote the four monthly sea temperatures observed at the light vessel at the start of the current measurements.

From the results of the 1950 cruises it had been deduced that the corner current may run most strongly around Lands End at neaps and be held back at springs. Consequently for each lunar month of the 1939-4I measurements we calculated the daily deviations from the mean direction of the water movement appropriate for that month. From these for each day of the generalized lunar month an average deviation of the direction of the residual water movement, clockwise or anti-clockwise, was obtained (Fig. 3, lower).

These deviations (maximum $27^{\circ}$ ) were of the same order as the error of single measurements. Nevertheless, it is reasonably certain that the residual water movement deviates to the northward of the mean in the vicinity of the springs and to the southward in the vicinity of the neaps. The deviation is greater at neaps than at springs but occurs for a shorter period. There are marked 'reactionary' deviations on either side of new moon, however, and 


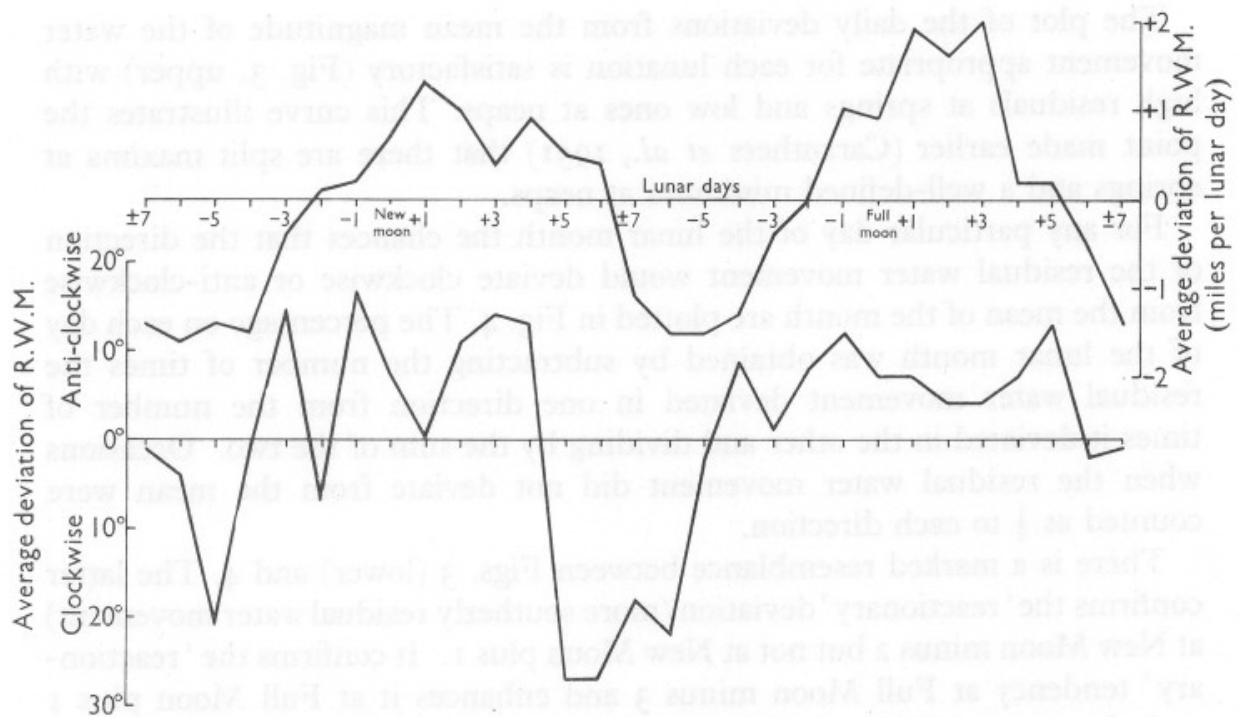

Fig. 3. The average deviation of the residual water movement from the mean for each lunation (lunar month) drawn for each day of the generalized lunation. Upper panel, magnitude in miles per lunar day; lower panel, direction.

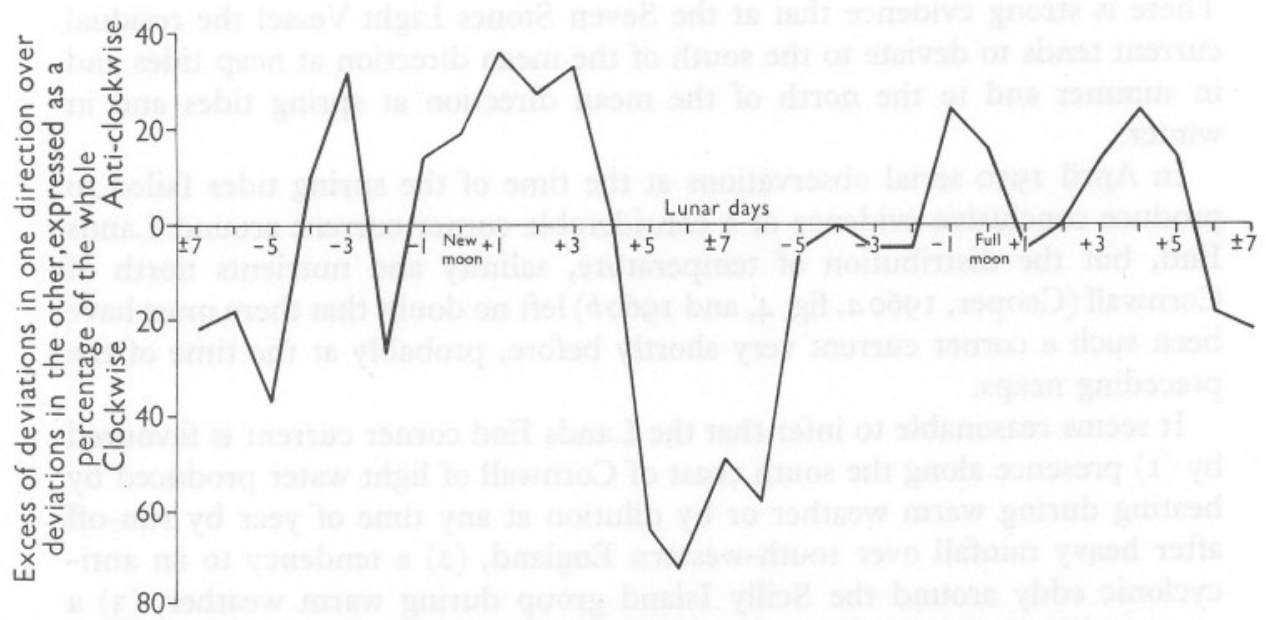

Fig. 4. Frequency of deviations of the residual water movement from the mean for each day of the lunar month.

less marked ones on either side of full moon. It is just possible that this may be due to the wind, on the majority of days involved, being unfavourable to the intrinsic direction of the residual water movements but, as the plot is for a mean of 22 lunar months it is more likely that there is in fact some reaction towards the opposite side of the mean direction for the month. 
The plot of the daily deviations from the mean magnitude of the water movement appropriate for each lunation is satisfactory (Fig. 3, upper) with high residuals at springs and low ones at neaps. This curve illustrates the point made earlier (Carruthers et al., I95I) that there are split maxima at springs and a well-defined minimum at neaps.

For any particular day of the lunar month the chances that the direction of the residual water movement would deviate clockwise or anti-clockwise from the mean of the month are plotted in Fig. 4. The percentage on each day of the lunar month was obtained by subtracting the number of times the residual water movement deviated in one direction from the number of times it deviated in the other and dividing by the sum of the two. Occasions when the residual water movement did not deviate from the mean were counted as $\frac{1}{2}$ to each direction.

There is a marked resemblance between Figs. 3 (lower) and 4. The latter confirms the 'reactionary' deviation (more southerly residual water movement) at New Moon minus 2 but not at New Moon plus I. It confirms the 'reactionary' tendency at Full Moon minus 3 and enhances it at Full Moon plus I and plus 2.

\section{DISCUSSION}

There is strong evidence that at the Seven Stones Light Vessel the residual current tends to deviate to the south of the mean direction at neap tides and in summer and to the north of the mean direction at spring tides and in winter.

In April 1950 serial observations at the time of the spring tides failed to produce conclusive evidence of a considerable corner current around Lands End, but the distribution of temperature, salinity and nutrients north of Cornwall (Cooper, $1960 a$, fig. 4, and $1960 b$ ) left no doubt that there must have been such a corner current very shortly before, probably at the time of the preceding neaps.

It seems reasonable to infer that the Lands End corner current is favoured by (I) presence along the south coast of Cornwall of light water produced by heating during warm weather or by dilution at any time of year by run-off after heavy rainfall over south-western England, (2) a tendency to an anticyclonic eddy around the Scilly Island group during warm weather, (3) a current direction at the Seven Stones Light Vessel setting well to the south of the Runnelstone, (4) weak currents at the light vessel, (5) neap tides (i.e. that the Lands End corner current will be most evident during neap tides in very warm or very wet weather).

Conversely, the Lands End corner current may be hindered by (I) homogeneous water stretching south of Cornwall, as after a heavy south-westerly gale, (2) a tendency to a cyclonic eddy around the Scilly Island group during cold weather, (3) a current at the Seven Stones lightvessel setting east towards 
the Lands End promontory, (4) spring tides, though these may mix waters ready to be carried around on the following neap tides.

Our argument has included neither what may happen when the current at the lightvessel sets towards a northerly or westerly direction, nor what may happen during severe gales which may override the forces acting during moderate winds.

\section{SUMMARY}

On a first appreciation, findings during the cruise of the Plymouth research vessel 'Sabella' around Lands End in April I950 appeared to conflict with conclusions drawn from long-period measurements of current at the Seven Stones Light Vessel. The results could be harmonized if it is assumed that there may be a narrow intermittent current around Lands End, transporting water from the south to the north coast of Cornwall and rarely extending as far west as the Seven Stones Light Vessel.

A detailed examination gave strong support to this explanation but the desired direct confirmation has, unfortunately, not yet been attempted.

The conclusions are set out in the Discussion.

\section{REFERENCES}

Carruthers, J. N., I934. The flow of water past the Seven Stones Lightvessel. f. mar. biol. Ass. U.K., Vol. 19, pp. $92 \mathrm{I}-30$.

Carruthers, J. N., Lawford, A. L. \& Veley, V. F. C., I95I. Studies of water movements and winds at various lightvessels. II. At the Seven Stones Lightvessel near the Scilly Islands. F. mar. biol. Ass. U.K., Vol. 29, pp. 587-608.

COOPER, L. H. N., 1960 $a$. Some theorems and procedures in shallow-water oceanography applied to the Celtic Sea. F. mar. biol. Ass. U.K., Vol. 39, pp. I55-7I.

- $1960 b$. Exchanges of water between the English and Bristol Channel around Lands End. 7. mar. biol. Ass. U.K., Vol. 39, pp. 637-58.

Harvey, H. W., 1925. Hydrography of the English Channel. Rapp. Cons. Explor. Mer, Vol. 37, pp. 59-89.

- 1929. Hydrodynamics of the waters south east of Ireland. F. Cons. int. Explor. Mer, Vol. 4, pp. 80-92.

Matthews, D. J., I9I4. The salinity and temperature of the Irish Channel and the waters south of Ireland. Sci. Invest. Fish Br. Ire., 1913, No. 4, 26 pp. 